\title{
Hypoxia and hypoxia-inducible factors in chronic kidney disease
}

\author{
Shinji Tanaka, Tetsuhiro Tanaka ${ }^{*}$ and Masaomi Nangaku
}

\begin{abstract}
It is generally accepted that renal hypoxia plays an important role in the progression of chronic kidney disease (CKD). This review focuses on renal hypoxia and hypoxia-inducible factor (HIF), a master regulator of cellular adaptation to hypoxia, during CKD progression. The kidney, which is physiologically hypoxic, is exposed to increased levels of hypoxia in CKD; insufficient oxygenation in the tubulointerstitium triggers injury and accelerates the deterioration of renal function, culminating in end-stage kidney disease (ESKD). HIF accumulates during specific stages of pathological progression; however, adaptation to hypoxia usually fails. In such cases, decreased vascular endothelial growth factor expression and upregulated antiangiogenic factors result in sustained capillary rarefaction. In addition, oxygen consumption in tubules is primarily increased by enhanced oxidative stress, and the transcriptional activity of HIF becomes suboptimal, which is partly mediated by methylglyoxal in diabetic kidney disease and by indoxyl sulfate, a representative uremic toxin, in advanced CKD. Oxygen-dependent canonical regulators of HIF involve prolyl hydroxylase domain-containing protein (PHD) and factor inhibiting HIF-1 (FIH-1), whereas recent studies have revealed noncanonical and oxygen-independent HIF regulation in the kidney. As a consequence, HIF accumulation usually fails to protect the kidney against hypoxia, which is likely to accelerate progression to ESKD, via several maladaptation mechanisms. The precise roles of HIF and its regulation in CKD warrant further investigation in light of promising data demonstrating that HIF stabilization by PHD inhibitors may be a new therapeutic approach for CKD.
\end{abstract}

Keywords: Hypoxia, Hypoxia-inducible factor, HIF, Chronic kidney disease, CKD, Prolyl hydroxylase, PHD, Indoxyl sulfate, Uremic toxin

\section{Background}

The worldwide disease burden of chronic kidney disease (CKD) has become an urgent issue; however, new therapeutic options for CKD are limited. Renal hypoxia plays an important role in the pathophysiology of acute kidney injury (AKI) and CKD $[1,2]$. It is now broadly accepted that activation of hypoxia-inducible factor (HIF), which is a key transcription factor in cellular adaptation to hypoxia, protects the kidney during AKI. However, the protective role of chronic HIF activation in CKD remains somewhat controversial. In this review, we discuss the roles of hypoxia and HIF in CKD, with a focus on HIF regulatory mechanisms, maladaptation to hypoxia, and HIF stabilization as a therapeutic strategy.

\footnotetext{
* Correspondence: tetsu-tky@umin.ac.jp

Division of Nephrology and Endocrinology, The University of Tokyo Graduate School of Medicine, 7-3-1 Hongo, Bunkyo-ku, Tokyo 113-8655, Japan
}

\section{Hypoxia in the kidney}

The kidney is physiologically considered hypoxic despite receiving up to $20 \%$ of the cardiac output in humans. Oxygen pressure in the renal cortex of normal animals is reportedly between 10 and $60 \mathrm{mmHg}$, whereas the corticomedullary junction and medulla are exposed to marked hypoxia [3-7]. One critical cause of kidney hypoxia, particularly in the medulla, is the arterial-venous oxygen shunt $[5,6,8]$. Another reason is that the kidney is required to reabsorb very high quantities of solutes (especially $\mathrm{Na}^{+}$) and water, which requires high levels of mitochondrial respiration and ATP production.

Based on these characteristics, Fine et al. [9] proposed that hypoxia in the tubulointerstitium of diseased kidneys is the final common pathway toward end-stage kidney disease (ESKD). Indeed, various methods have revealed aggravated renal hypoxia in numerous animal models of CKD [1]. Furthermore, in several human studies, blood oxygen level-dependent magnetic resonance imaging 
successfully demonstrated a correlation between renal oxygenation levels and estimated glomerular filtration rate [10]. The chronic hypoxia hypothesis has been validated by many groups including ours, and renal hypoxia in CKD is broadly accepted as a key player in ESKD development [11-14].

\section{HIF}

HIF, a key transcription factor that facilitates cellular adaptation to hypoxia, consists of $\alpha$ and $\beta$ subunits. Of these, HIF- $\alpha$ has two major active isoforms, HIF- $1 \alpha$ and HIF- $2 \alpha$. HIF- $1 \alpha$ is primarily expressed in the tubular epithelial cells of the hypoxic kidney and functions as a master regulator of cellular adaptation to hypoxia $[15,16]$. In contrast, the expression of HIF- $2 \alpha$ in the hypoxic kidney is limited to the endothelial and interstitial cells. Recent studies have revealed that renal erythropoietin (EPO) is produced in fibroblast-like cells in the interstitium in a HIF-2 $\alpha$ dependent manner [17-19].

HIF- $\beta$ is constitutively expressed, whereas HIF- $\alpha$ expression is significantly dependent on oxygen tension levels. Under normoxic conditions, prolyl hydroxylase domain-containing proteins (PHDs) hydroxylate specific proline residues on HIF- $\alpha$, which allows it to be recognized by von Hippel-Lindau tumor suppressor protein ( $\mathrm{pVHL}$ ), to be polyubiquitinated and degraded in the proteasome $[20,21]$. In contrast, under hypoxic conditions, HIF- $\alpha$ escapes PHD-mediated hydroxylation, translocates to the nucleus, and forms a heterodimer with HIF- $\beta$. HIF heterodimers bind to hypoxia response elements in the regulatory regions of $>100$ target genes (e.g., EPO, vascular endothelial growth factor (VEGF), and glycolytic enzymes), resulting in transactivation of these genes [22].

Under normoxic conditions, HIF- $1 \alpha$ undergoes another post-translational modification by factor inhibiting HIF-1 (FIH-1), an asparaginyl hydroxylase that hydroxylates one specific asparagine residue of HIF- $1 \alpha$. This modification inhibits the binding of coactivators p300 and CREB-binding protein (CBP), resulting in repressed transactivation [1]. FIH-1 is abundantly expressed in distal tubules and podocytes [23], and it exhibits a lower $K_{\mathrm{m}}$ value for oxygen than PHD; thus, in a certain range of oxygen tension, HIF- $1 \alpha$ that is stabilized by escaping degradation via the PHD/ pVHL pathway still undergoes FIH-1-mediated, oxygendependent transactivational regulation (Fig. 1) [24].

\section{Diverse regulatory mechanisms of HIF signaling: beyond PHD/FIH}

Accumulating evidence suggests that HIF activity is finely tuned by various oxygen-independent pathways $[24,25]$. Besides PHD-dependent HIF- $\alpha$ degradation, oxygen-independent HIF- $1 \alpha$ degradation mechanisms exist. For example, the receptor of activated protein kinase C 1 (RACK1) competes with heat-shock protein
(HSP) 90, which stabilizes HIF-1 $\alpha$, to bind to HIF- $1 \alpha$ and elongin $C$, resulting in enhanced HIF- $1 \alpha$ ubiquitination [26]. A role of HSPs and the carboxy terminus of HSP70-interacting protein (CHIP), an ubiquitin ligase, has also been shown in HIF-1 $\alpha$ degradation [27-29]. Hypoxia-associated factor, an E3 ubiquitin ligase, also reportedly binds to HIF- $1 \alpha$ and facilitates its proteasomal degradation even under normoxic conditions [30].

Post-translational modifications of HIF- $1 \alpha$ and HIF- $2 \alpha$ at specific residues, such as phosphorylation [31, 32], acetylation [33, 34], S-nitrosylation [35, 36], and sumoylation [37, 38], are suggested to affect HIF protein stability and transactivation activity; however, the exact mechanisms of these HIF modifications remain unclear, and further work is required to clarify the precise roles of these modifications.

HIF- $\alpha$ has also been demonstrated to undergo transcriptional and translational regulation [39, 40]. For example, bacterial products recognized by Toll-like receptors can upregulate HIF-1 $\alpha$ messenger RNA (mRNA) levels in myeloid cells through a nuclear factor- $k \mathrm{~B}$ (NF- $\mathrm{kB}$ )dependent pathway [41]. T-cell receptor ligation on $\mathrm{T}$ lymphocytes also results in increased HIF- $\alpha$ mRNA levels [42, 43]. Furthermore, increased HIF-1 $\alpha$ translation via the phosphatidylinositol 3-kinase (PI3K)/AKT/mammalian target of rapamycin (mTOR) pathway was also demonstrated in vascular smooth muscle cells [44] and cancer cells [45].

\section{Noncanonical HIF regulation in the kidney}

Noncanonical HIF regulation that was, until recently, believed to occur in tumor and immune cells [46] has recently been shown to occur in the intrinsic cells of kidneys (Table 1).

CCAAT/enhancer-binding protein $\delta$ (CEBPD) was shown to be induced in tubular epithelial cells via a HIF-1-independent pathway in both acute and chronic hypoxic kidneys [47]. It directly binds to the HIF-1 $\alpha$ promoter and enhances its transcription. Importantly, CEBPD is also induced by inflammatory stimuli, such as interleukin- $1 \beta$, resulting in increased HIF- $1 \alpha$ expression even under normoxic conditions. These findings indicate that CEBPD is a potential role player in the association between inflammation and hypoxia in the kidney.

Recent studies have shown that HIF- $2 \alpha$ is also regulated by several mechanisms in the kidney. Iron regulatory protein 1 (IRP1), which plays a central role in cellular iron metabolism regulation, is activated in iron-deficient cells and inactivated under hypoxia $[48,49]$. Polysome profiling analysis revealed that a larger proportion of HIF- $2 \alpha$ mRNA is translationally active in the kidney of Irp1-/mice, resulting in increased renal EPO expression and marked polycythemia; thus, IRP1 may regulate HIF- $2 \alpha$ protein levels through translational repression [50]. 


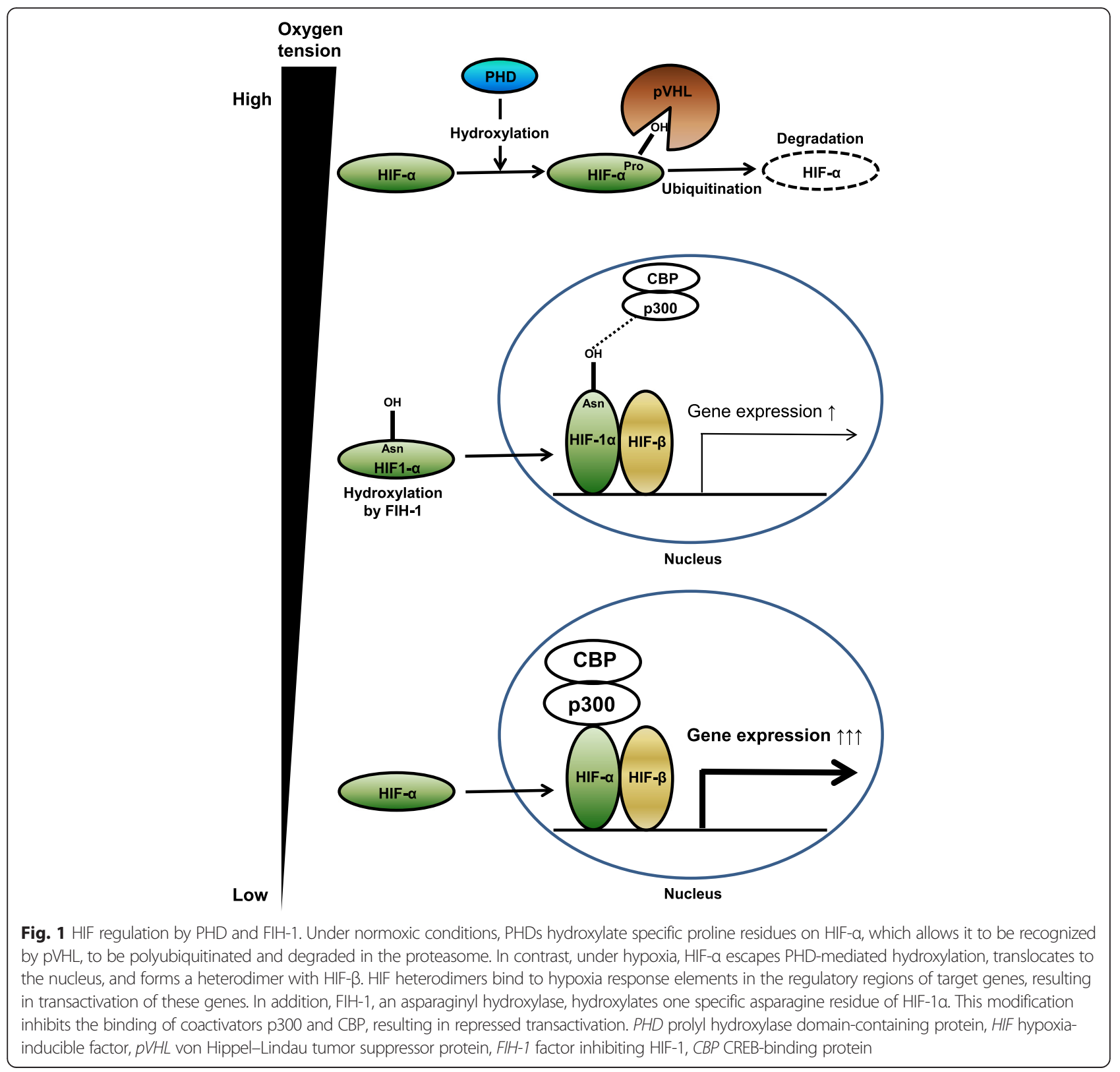

Acetylation/deacetylation of HIF- $2 \alpha$ is also emerging as a key step in EPO gene expression. Garcia and colleagues $[51,52]$ demonstrated that acetyl CoA synthetase 2dependent HIF- $2 \alpha$ acetylation at specific lysine residues by $\mathrm{CBP}$ and formation of the CBP-HIF- $2 \alpha$ complex are essential for the efficient induction of EPO in the kidney and liver under hypoxic conditions. They also showed that HIF- $2 \alpha$ acetylation under hypoxia is reversed, i.e., deacetylated, by Sirtuin 1 (Sirt1) and that the deacetylation process augments rather than dampens HIF-2 signaling [53]. Although the precise mechanism is yet to be determined, this cyclical acetylation by CBP and deacetylation by Sirt1 appears to be necessary for efficient HIF-2 signaling during hypoxia rather than being only an on/off switch $[52,54]$.

\section{Maladaptation to hypoxia during CKD progression}

As discussed above, advanced renal hypoxia is observed in animal and human CKD. Despite several controversies, HIF accumulation has been shown to occur at certain stages during CKD, which is expected to protect against hypoxia [55-57]. Nevertheless, in many CKD patients, kidney hypoxia does not improve and is rather aggravated, and renal function shows a sustained decline, 
Table 1 Noncanonical HIF regulation in the kidney

\begin{tabular}{lll}
\hline Cell type & Regulators & Principal changes \\
\hline Tubular epithelial cell & Indoxyl sulfate [78] & HIF-1 transactivation activity $\downarrow$ \\
& CEBPD [47] & HIF-1a mRNA $\uparrow$ \\
EPO-producing cell & TGF- $\beta 1 /$ Smad3/mTORC1 $[95,96]$ & HIF-1a protein $\uparrow$ \\
Endothelial cell & IRP1 [50] & HIF-2a protein $\downarrow$ \\
Mesangial cell & LPS/NF-KB [97] & HIF-2a mRNA $\uparrow$ \\
HFF-1
\end{tabular}

HIF hypoxia-inducible factor, CEBPD CCAAT/enhancer-binding protein $\delta, T G F-\beta 1$ transforming growth factor- $\beta 1$, Smad3 mothers against decapentaplegic homolog 3, mTORC1 mammalian target of rapamycin complex 1, EPO erythropoietin, IRP1 iron regulatory protein 1, LPS lipopolysaccharide, NF-KB nuclear factor-KB

resulting in ESKD. To date, several possible mechanisms have been proposed, which are discussed below (Fig. 2).

\section{Sustained capillary rarefaction}

Capillary rarefaction in the kidney is a common feature that is intricately linked to hypoxia in CKD [58]. In human kidney biopsy samples, capillary densities are significantly associated with renal function. Although HIF likely upregulates angiogenic factors, such as VEGF, that theoretically leads to the restoration of capillary densities, this adaptation mechanism usually fails; thus, capillary rarefaction is sustained and progressive. Several possibilities have been suggested to explain the failure of capillary restoration [59]. First, VEGF expression in the kidney is decreased in CKD, which may indicate that damaged tubular epithelial cells do not produce sufficient VEGF [60]. The inflammatory environment, which is intricately linked to CKD, may also suppress VEGF expression [61]. Second, antiangiogenic factors (e.g., thrombospondin 1 and endostatin) have been reported to be upregulated in several kidney diseases [61-63]. Third, the incompetence of endothelial progenitor cells potentially underlies insufficient capillary restoration [64], although recent studies have questioned the direct involvement of bone marrow-derived or circulating progenitor/stem cells in blood vessel regeneration $[65,66]$.

\section{Increased oxygen consumption in tubules}

Various factors are suggested to increase oxygen consumption in damaged tubules. Welch et al. [67, 68] demonstrated increased oxygen consumption and decreased oxygen levels in the kidneys of angiotensin IIinfused or spontaneously hypertensive rats. These changes are probably because of oxidative stress induced by angiotensin II, based on the restoration of normal oxygen metabolism by the administration of tempol or an angiotensin II receptor blocker. Indoxyl sulfate, a representative uremic toxin, may also be involved in increased oxygen consumption in uremic kidneys via enhanced oxidative

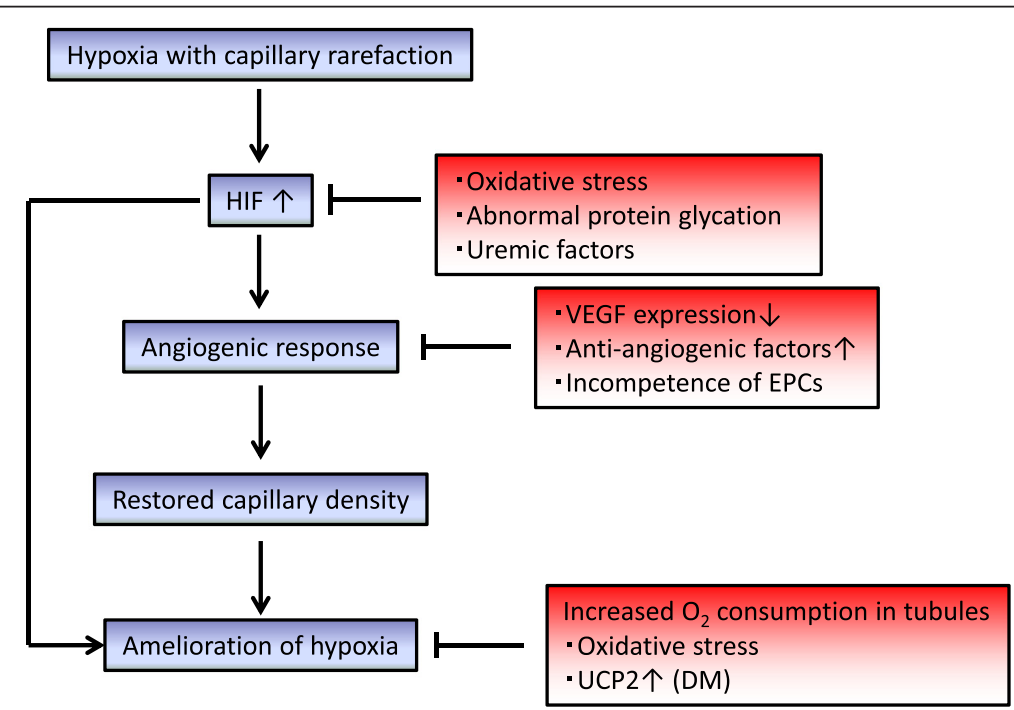

Fig. 2 Maladaptation to hypoxia during CKD progression. HIF accumulation occurring at certain stages during CKD is expected to protect the kidney against hypoxia (blue squares on the left). Nevertheless, in many CKD patients, kidney hypoxia does not improve, resulting in ESKD via several mechanisms (red squares on the right). Further details are explained in the text. HIF hypoxia-inducible factor, DM diabetes mellitus, VEGF vascular endothelial growth factor, EPC endothelial progenitor cell, UCP2 uncoupling protein 2 
stress [69]. Moreover, in diabetic kidney disease, upregulated mitochondrial uncoupling protein-2 is suggested to increase oxygen consumption in exchange of reducing oxidative stress [70, 71].

\section{Impaired HIF activation}

Activation of HIF in the kidney may be suboptimal in CKD despite profound renal hypoxia. This concept is best exemplified in diabetic kidneys [72, 73] but may apply in CKD of nondiabetic etiologies.

A large body of evidence suggests that cellular adaptation to hypoxia is impaired in the diabetic milieu and that deregulated HIF- $1 \alpha$ may be a significant contributor $[74,75]$. Methylglyoxal, a highly reactive dicarbonyl metabolite that is increased in diabetes, has been shown to be a key player in the impairment of the HIF-1 pathway. Methylglyoxal modifies specific arginine residues in HIF- $1 \alpha$ and blocks heterodimer formation with HIF-1 $\beta$ [76]. The interaction between HIF- $1 \alpha$ and p300 is also inhibited by methylglyoxal via modification of an asparagine residue at p300 [77]. In addition to the functional suppression of HIF-1, methylglyoxal may inhibit HIF-1 activity via enhanced degradation. Bento et al. [29] demonstrated that methylglyoxal increased association of HIF$1 \alpha$ with HSP40 and HSP70, leading to CHIP recruitment and polyubiquitination of HIF- $1 \alpha$. This may be because of the increased levels of modified and monomeric HIF- $1 \alpha$ resulting from the inhibited association of HIF- $1 \alpha$ with HIF- $1 \beta$ and $\mathrm{p} 300$.

Additional mechanisms of the suppression of HIF activation in advanced CKD, including nondiabetic etiologies, have been proposed. We previously reported that at clinically relevant concentrations, indoxyl sulfate upregulated $\mathrm{CBP} / \mathrm{p} 300$-interacting transactivator with Glu/Asp-rich carboxy-terminal domain 2 (CITED2) via post-transcriptional mRNA stabilization, which in turn inhibited the interaction between p300 and HIF-1 $\alpha$ Cterminal transactivation domain, resulting in suppressed HIF-1 transactivation activity [78]. Deficient HIF-1 transcriptional activity may also be caused by a decrease in the expression of p300/CBP-associated factor, which is observed in adipose tissue-derived mesenchymal stem cells of dialysis patients as compared with those of nondialysis patients [79].

\section{Link between hypoxia and epigenetic changes in CKD}

With recent technological advances in epigenetics, much attention is currently focused on the pathophysiological roles of epigenetic changes in CKD, specifically sustained CKD progression and AKI-to-CKD transition [80, 81]. Accumulating data have demonstrated that hypoxia can induce epigenetic changes to promote profibrotic and proinflammatory gene expression [82]. Indeed, under hypoxic conditions, HIF-1 binds to the promoters of genes encoding two histone demethylases, JMJD1A and JMJD2B, to induce their expression, which in turn enhances the expression of downstream genes by decreasing promoter histone methylation [83, 84]. Chromosome conformation capture assay has revealed that chromatin conformation may dramatically change depending on the interaction of HIF-1 with lysine-specific demethylase $3 \mathrm{~A}$, leading to the removal of a suppressive histone mark and upregulation of $S L C 2 A 3$ [85].

\section{HIF stabilization as a treatment of CKD}

Given that renal hypoxia is a final common pathway in CKD progression and that HIF activation in CKD appears to be suboptimal, HIF stabilization presents a reasonable target for CKD. This concept has been supported by numerous studies using several animal models of CKD [86-88]. Recently, Palm and colleagues [89] demonstrated that the administration of cobalt ameliorated kidney damage in streptozotocin-induced diabetic rats, which was accompanied by increased oxygen tension in the kidney. However, these studies have several limitations. Polycythemia, which is frequently observed in studies with chronic HIF stabilization, may have confounding effects on the kidney. Moreover, cobalt, which has been used to stabilize HIF in numerous studies, has systemic effects, such as body weight loss, with $<30 \%$ overlap of gene expression changes by treatment with cobalt and hypoxia $[90,91]$. Therefore, the usefulness of HIF stabilization in CKD should be investigated in animal and clinical studies by using specific PHD inhibitors, which are being developed as therapeutics against renal anemia.

Taking into consideration that inappropriate HIF activation may lead to serious adverse effects, such as fibrogenesis [92] and tumorigenesis [93], several conceptual hurdles need to be overcome; it is clear that the HIF stabilization approach necessitates several critical parameters to be determined, i.e., to what extent, when, and where. It should be noted that genetic manipulation generally results in more profound phenotypes than pharmacological intervention, and the consequences of pharmacological HIF activation by PHD inhibitors and genetic manipulation of Phd, Hif, or $\mathrm{Vhl}$ could yield inconsistent findings. In addition, the optimal timing for HIF stabilization should be determined because the outcomes of HIF stabilization can be both beneficial and detrimental, depending on its timing [94]. Lastly, because HIF plays different roles in various cell types in the kidney, the consequences of systemic HIF stabilization may vary widely, depending on the context. Cell type-specific HIF stabilization is certainly an attractive idea to achieve a safe and effective treatment; however, a much deeper understanding of HIF 
regulation in each cell type (e.g., cell type-specific transcriptional coactivators) is required.

\section{Conclusions}

Renal hypoxia is now regarded as a key player in the progression of CKD. HIF is a master regulator that helps cells to cope with hypoxia, and additional mechanisms of HIF regulation, other than those mediated by $\mathrm{PHD} / \mathrm{FIH}$, have recently been clarified in the kidney. Although HIF most likely accumulates at certain stages during CKD pathogenesis, maladaptation to hypoxia frequently occurs in CKD via several mechanisms, which include sustained capillary rarefaction, increased oxygen consumption in tubules, and impaired HIF activation, culminating in progression to ESKD. Considering experimental evidence that suboptimal HIF activation is observed in CKD, its stabilization is a new and promising therapeutic target in CKD; however, a deeper understanding of the mechanisms of HIF regulation and its potential protective role in the diseased kidney are essential for its safe and efficient clinical application in the future.

\section{Competing interests}

M. N. serves as an advisor of GSK, Taisho, and Astellas.

\section{Authors' contributions}

ST, T, and MN drafted the manuscript. All authors read and approved the final manuscript.

\section{Acknowledgements}

The work of the authors is supported by a Grant-in-Aid for Scientific Research on Innovative Areas from the Ministry of Education, Culture, Sports, Science, and Technology of Japan 26111003 (M. N.) and a Grant-in-Aid for Scientific Research from the Japan Society for the Promotion of Science 24390213 (M. N.) and 26461215 (T. T.).

Received: 6 November 2015 Accepted: 30 March 2016 Published online: 06 July 2016

\section{References}

1. Nangaku M, Rosenberger C, Heyman SN, Eckardt KU. Regulation of hypoxiainducible factor in kidney disease. Clin Exp Pharmacol Physiol. 2013:40:148-57.

2. Mimura I, Nangaku M. The suffocating kidney: tubulointerstitial hypoxia in end-stage renal disease. Nat Rev Nephrol. 2010;6:667-78.

3. Brezis M, Rosen S. Hypoxia of the renal medulla -its implications for disease. N Engl J Med. 1995;332:647-55.

4. Liss P, Nygren A, Revsbech NP, Ulfendahl HR. Intrarenal oxygen tension measured by a modified Clark electrode at normal and low blood pressure and after injection of x-ray contrast media. Pflugers Arch. 1997:434:705-11.

5. Schurek HJ, Jost U, Baumgärtl $H$, Bertram H, Heckmann U. Evidence for a preglomerular oxygen diffusion shunt in rat renal cortex. Am J Physiol. 1990; 259:F910-5.

6. Welch WJ, Baumgärtl H, Lübbers D, Wilcox CS. Nephron po2 and renal oxygen usage in the hypertensive rat kidney. Kidney Int. 2001;59:230-7.

7. Whitehouse T, Stotz M, Taylor V, Stidwill R, Singer M. Tissue oxygen and hemodynamics in renal medulla, cortex, and corticomedullary junction during hemorrhage-reperfusion. Am J Physiol Renal Physiol. 2006;291:F647-53.

8. LEVY MN, SAUCEDA G. Diffusion of oxygen from arterial to venous segments of renal capillaries. Am J Physiol. 1959;196:1336-9.

9. Fine LG, Bandyopadhay D, Norman JT. Is there a common mechanism for the progression of different types of renal diseases other than proteinuria? Towards the unifying theme of chronic hypoxia. Kidney Int Suppl United States. 2000;75:S22-6.
10. Inoue T, Kozawa E, Okada H, Inukai K, Watanabe S, Kikuta T, et al. Noninvasive evaluation of kidney hypoxia and fibrosis using magnetic resonance imaging. J Am Soc Nephrol. 2011;22:1429-34.

11. Nangaku M. Chronic hypoxia and tubulointerstitial injury: a final common pathway to end-stage renal failure. J Am Soc Nephrol. 2006;17:17-25.

12. Eckardt KU, Bernhardt WM, Weidemann A, Warnecke C, Rosenberger C, Wiesener MS, Willam C. Role of hypoxia in the pathogenesis of renal disease. Kidney Int Suppl. 2005;99:S46-51.

13. Eckardt KU, Rosenberger C, Jürgensen JS, Wiesener MS. Role of hypoxia in the pathogenesis of renal disease. Blood Purif. 2003;21:253-7.

14. Heyman SN, Khamaisi M, Rosen S, Rosenberger C. Renal parenchymal hypoxia, hypoxia response and the progression of chronic kidney disease. Am J Nephrol. 2008;28:998-1006.

15. Rosenberger C, Mandriota S, Jürgensen JS, Wiesener MS, Hörstrup JH, Frei U, et al. Expression of hypoxia-inducible factor-1alpha and -2alpha in hypoxic and ischemic rat kidneys. J Am Soc Nephrol. 2002;13:1721-32.

16. Wiesener MS, Jürgensen JS, Rosenberger C, Scholze CK, Hörstrup JH, Warnecke C, et al. Widespread hypoxia-inducible expression of hif-2alpha in distinct cell populations of different organs. FASEB J. 2003;17:271-3.

17. Souma T, Yamazaki S, Moriguchi T, Suzuki N, Hirano I, Pan X, et al. Plasticity of renal erythropoietin-producing cells governs fibrosis. J Am Soc Nephrol. 2013;24:1599-616.

18. Tan Q, Kerestes H, Percy MJ, Pietrofesa R, Chen L, Khurana TS, et al. Erythrocytosis and pulmonary hypertension in a mouse model of human hif2a gain of function mutation. J Biol Chem. 2013;288:17134-44.

19. Souma T, Nezu M, Nakano D, Yamazaki S, Hirano I, Sekine H, et al. Erythropoietin synthesis in renal myofibroblasts is restored by activation of hypoxia signaling. J Am Soc Nephrol. 2016;27:428-38.

20. Ivan M, Kondo K, Yang H, Kim W, Valiando J, Ohh M, et al. Hifalpha targeted for vhl-mediated destruction by proline hydroxylation: implications for 02 sensing. Science. 2001;292:464-8.

21. Jaakkola P, Mole DR, Tian YM, Wilson MI, Gielbert J, Gaskell SJ, et al. Targeting of hif-alpha to the von hippel-lindau ubiquitylation complex by o2-regulated prolyl hydroxylation. Science. 2001;292:468-72.

22. Nangaku M, Eckardt KU. Hypoxia and the hif system in kidney disease. J Mol Med (Berl). 2007;85:1325-30.

23. Schödel J, Bohr D, Klanke B, Schley G, Schlötzer-Schrehardt U, Warnecke C, et al. Factor inhibiting hif limits the expression of hypoxia-inducible genes in podocytes and distal tubular cells. Kidney Int. 2010;78:857-67.

24. Dengler VL, Galbraith MD, Espinosa JM. Transcriptional regulation by hypoxia inducible factors. Crit Rev Biochem Mol Biol. 2014;49:1-15.

25. Brocato J, Chervona Y, Costa M. Molecular responses to hypoxia-inducible factor 1a and beyond. Mol Pharmacol. 2014;85:651-7.

26. Liu Y, Baek JH, Zhang H, Diez R, Cole RN, Semenza GL. Rack1 competes with hsp90 for binding to hif-1alpha and is required for o(2)-independent and hsp90 inhibitor-induced degradation of hif-1alpha. Mol Cell. 2007;25: 207-17.

27. Kong X, Lin Z, Liang D, Fath D, Sang N, Caro J. Histone deacetylase inhibitors induce vhl and ubiquitin-independent proteasomal degradation of hypoxia-inducible factor 1alpha. Mol Cell Biol. 2006;26:2019-28.

28. Luo W, Zhong J, Chang R, Hu H, Pandey A, Semenza GL. Hsp70 and chip selectively mediate ubiquitination and degradation of hypoxia-inducible factor (hif)-1alpha but not hif-2alpha. J Biol Chem. 2010;285:3651-63.

29. Bento CF, Fernandes R, Ramalho J, Marques C, Shang F, Taylor A, et al. The chaperone-dependent ubiquitin ligase chip targets hif-1a for degradation in the presence of methylglyoxal. PLoS One. 2010;5:e15062.

30. Koh MY, Darnay BG, Powis G. Hypoxia-associated factor, a novel e3-ubiquitin ligase, binds and ubiquitinates hypoxia-inducible factor 1alpha, leading to its oxygen-independent degradation. Mol Cell Biol. 2008;28:7081-95.

31. Richard DE, Berra E, Gothié E, Roux D, Pouysségur J. P42/p44 mitogen-activated protein kinases phosphorylate hypoxia-inducible factor 1alpha (hif-1alpha) and enhance the transcriptional activity of hif-1. J Biol Chem. 1999;274:32631-7.

32. Kalousi A, Mylonis I, Politou AS, Chachami G, Paraskeva E, Simos G. Casein kinase 1 regulates human hypoxia-inducible factor hif-1. J Cell Sci. 2010;123: 2976-86.

33. Geng H, Harvey CT, Pittsenbarger J, Liu Q, Beer TM, Xue C, et al. Hdac4 protein regulates hif1a protein lysine acetylation and cancer cell response to hypoxia. J Biol Chem. 2011;286:38095-102.

34. Geng H, Liu Q, Xue C, David LL, Beer TM, Thomas GV, et al. Hif1 a protein stability is increased by acetylation at lysine 709. J Biol Chem. 2012;287: 35496-505. 
35. Cho H, Ahn DR, Park H, Yang EG. Modulation of p300 binding by posttranslational modifications of the c-terminal activation domain of hypoxia-inducible factor-1alpha. FEBS Lett. 2007;581:1542-8.

36. Yasinska IM, Sumbayev W. S-nitrosation of cys-800 of hif-1alpha protein activates its interaction with p300 and stimulates its transcriptional activity. FEBS Lett. 2003;549:105-9.

37. Bae SH, Jeong JW, Park JA, Kim SH, Bae MK, Choi SJ, et al. Sumoylation increases hif-1alpha stability and its transcriptional activity. Biochem Biophys Res Commun. 2004;324:394-400.

38. Berta MA, Mazure N, Hattab M, Pouysségur J, Brahimi-Horn MC. Sumoylation of hypoxia-inducible factor-1alpha reduces its transcriptional activity. Biochem Biophys Res Commun. 2007;360:646-52.

39. Semenza GL. Hif-1 mediates metabolic responses to intratumoral hypoxia and oncogenic mutations. J Clin Invest. 2013;123:3664-71.

40. Semenza GL. Targeting hif-1 for cancer therapy. Nat Rev Cancer. 2003;3:721-32.

41. Rius J, Guma M, Schachtrup C, Akassoglou K, Zinkernagel AS, Nizet V, et al. Nf-kappab links innate immunity to the hypoxic response through transcriptional regulation of hif-1alpha. Nature. 2008;453:807-11.

42. Dang EV, Barbi J, Yang HY, Jinasena D, Yu H, Zheng Y, et al. Control of t(h)17/t(reg) balance by hypoxia-inducible factor 1. Cell. 2011;146:772-84.

43. Doedens AL, Phan AT, Stradner MH, Fujimoto JK, Nguyen JV, Yang E, et al. Hypoxia-inducible factors enhance the effector responses of $\mathrm{cd} 8(+) \mathrm{t}$ cells to persistent antigen. Nat Immunol. 2013;14:1173-82.

44. Pagé EL, Robitaille GA, Pouysségur J, Richard DE. Induction of hypoxiainducible factor-1alpha by transcriptional and translational mechanisms. J Biol Chem. 2002;277:48403-9.

45. Hudson CC, Liu M, Chiang GG, Otterness DM, Loomis DC, Kaper F, et al. Regulation of hypoxia-inducible factor 1alpha expression and function by the mammalian target of rapamycin. Mol Cell Biol. 2002;22:7004-14.

46. Palazon A, Goldrath AW, Nizet V, Johnson RS. Hif transcription factors, inflammation, and immunity. Immunity. 2014;41:518-28.

47. Yamaguchi J, Tanaka T, Eto N, Nangaku M. Inflammation and hypoxia linked to renal injury by ccaat/enhancer-binding protein $\delta$. Kidney Int. 2015;88:262-75.

48. Hentze MW, Muckenthaler MU, Galy B, Camaschella C. Two to tango: Regulation of mammalian iron metabolism. Cell. 2010;142:24-38.

49. Anderson CP, Shen M, Eisenstein RS, Leibold EA. Mammalian iron metabolism and its control by iron regulatory proteins. Biochim Biophys Acta. 1823;2012:1468-83.

50. Anderson SA, Nizzi CP, Chang YI, Deck KM, Schmidt PJ, Galy B, et al. The irp1-hif-2a axis coordinates iron and oxygen sensing with erythropoiesis and iron absorption. Cell Metab. 2013;17:282-90.

51. Xu M, Nagati JS, Xie J, Li J, Walters H, Moon YA, et al. An acetate switch regulates stress erythropoiesis. Nat Med. 2014;20:1018-26.

52. Chen R, Xu M, Hogg RT, Li J, Little B, Gerard RD, et al. The acetylase/ deacetylase couple creb-binding protein/sirtuin 1 controls hypoxia-inducible factor 2 signaling. J Biol Chem. 2012;287:30800-11.

53. Dioum EM, Chen R, Alexander MS, Zhang Q, Hogg RT, Gerard RD, et al. Regulation of hypoxia-inducible factor 2alpha signaling by the stressresponsive deacetylase sirtuin 1. Science. 2009;324:1289-93.

54. Chen R, Xu M, Nagati JS, Hogg RT, Das A, Gerard RD, et al. The acetate/ acss 2 switch regulates hif-2 stress signaling in the tumor cell microenvironment. PLoS One. 2015:10:e0116515.

55. Goldfarb M, Rosenberger C, Abassi Z, Shina A, Zilbersat F, Eckardt KU, et al. Acute-on-chronic renal failure in the rat: functional compensation and hypoxia tolerance. Am J Nephrol. 2006;26:22-33.

56. Yu X, Fang Y, Ding X, Liu H, Zhu J, Zou J, et al. Transient hypoxia-inducible factor activation in rat renal ablation and reduced fibrosis with I-mimosine. Nephrology (Carlton). 2012;17:58-67.

57. Bernhardt WM, Wiesener MS, Weidemann A, Schmitt R, Weichert W, Lechler $P$, et al. Involvement of hypoxia-inducible transcription factors in polycystic kidney disease. Am J Pathol. 2007;170:830-42.

58. Tanaka T, Nangaku M. Angiogenesis and hypoxia in the kidney. Nat Rev Nephrol. 2013;9:211-22.

59. Tanaka S, Tanaka T, Nangaku M. Hypoxia and dysregulated angiogenesis in kidney disease. Kidney Dis. 2015;1:80-9.

60. Polichnowski AJ, Lan R, Geng H, Griffin KA, Venkatachalam MA, Bidani AK. Severe renal mass reduction impairs recovery and promotes fibrosis after aki. J Am Soc Nephrol. 2014;25:1496-507.

61. Kang DH, Joly AH, Oh SW, Hugo C, Kerjaschki D, Gordon KL, et al. Impaired angiogenesis in the remnant kidney model: I. Potential role of vascular endothelial growth factor and thrombospondin-1. J Am Soc Nephrol. 2001; 12:1434-47.

62. Long DA, Norman JT, Fine LG. Restoring the renal microvasculature to treat chronic kidney disease. Nat Rev Nephrol. 2012;8:244-50.

63. Maciel TT, Coutinho EL, Soares D, Achar E, Schor N, Bellini MH. Endostatin, an antiangiogenic protein, is expressed in the unilateral ureteral obstruction mice model. J Nephrol. 2008;21:753-60.

64. Goligorsky MS, Yasuda K, Ratliff B. Dysfunctional endothelial progenitor cells in chronic kidney disease. J Am Soc Nephrol. 2010;21:911-9.

65. Rinkevich Y, Lindau P, Ueno H, Longaker MT, Weissman IL. Germ-layer and lineage-restricted stem/progenitors regenerate the mouse digit tip. Nature. 2011;476:409-13.

66. Sradnick J, Rong S, Luedemann A, Parmentier SP, Bartaun C, Todorov VT, Gueler F, Hugo CP, Hohenstein B. Extrarenal progenitor cells do not contribute to renal endothelial repair. J Am Soc Nephrol. 2015; doi: 10.1681/ASN.2015030321.

67. Welch WJ, Baumgärtl H, Lübbers D, Wilcox CS. Renal oxygenation defects in the spontaneously hypertensive rat: role of at1 receptors. Kidney Int. 2003; 63:202-8.

68. Welch WJ, Blau J, Xie H, Chabrashvili T, Wilcox CS. Angiotensin-induced defects in renal oxygenation: role of oxidative stress. Am J Physiol Heart Circ Physiol. 2005;288:H22-8.

69. Palm F, Nangaku M, Fasching A, Tanaka T, Nordquist L, Hansell P, et al. Uremia induces abnormal oxygen consumption in tubules and aggravates chronic hypoxia of the kidney via oxidative stress. Am J Physiol Renal Physiol. 2010;299:F380-6.

70. Friederich M, Fasching A, Hansell P, Nordquist L, Palm F. Diabetes-induced up-regulation of uncoupling protein-2 results in increased mitochondrial uncoupling in kidney proximal tubular cells. Biochim Biophys Acta. 2008; 1777:935-40.

71. Persson MF, Franzén S, Catrina SB, Dallner G, Hansell P, Brismar K, et al. Coenzyme q10 prevents gdp-sensitive mitochondrial uncoupling, glomerular hyperfiltration and proteinuria in kidneys from $\mathrm{db} / \mathrm{db}$ mice as a model of type 2 diabetes. Diabetologia. 2012;55:1535-43.

72. Rosenberger C, Khamaisi M, Abassi Z, Shilo V, Weksler-Zangen S, Goldfarb M, et al. Adaptation to hypoxia in the diabetic rat kidney. Kidney Int. 2008;73: 34-42.

73. Katavetin P, Miyata T, Inagi R, Tanaka T, Sassa R, Ingelfinger JR, et al. High glucose blunts vascular endothelial growth factor response to hypoxia via the oxidative stress-regulated hypoxia-inducible factor/hypoxia-responsible element pathway. J Am Soc Nephrol. 2006;17:1405-13.

74. Bento CF, Pereira P. Regulation of hypoxia-inducible factor 1 and the loss of the cellular response to hypoxia in diabetes. Diabetologia. 2011;54:1946-56.

75. Catrina SB. Impaired hypoxia-inducible factor (hif) regulation by hyperglycemia. J Mol Med (Berl). 2014;92:1025-34.

76. Ceradini DJ, Yao D, Grogan RH, Callaghan MJ, Edelstein D, Brownlee M, et al. Decreasing intracellular superoxide corrects defective ischemia-induced new vessel formation in diabetic mice. J Biol Chem. 2008;283:10930-8.

77. Thangarajah H, Yao D, Chang El, Shi Y, Jazayeri L, Vial IN, et al. The molecular basis for impaired hypoxia-induced vegf expression in diabetic tissues. Proc Natl Acad Sci U S A. 2009;106:13505-10.

78. Tanaka T, Yamaguchi J, Higashijima Y, Nangaku M. Indoxyl sulfate signals for rapid mrna stabilization of $\mathrm{cbp} / \mathrm{p} 300$-interacting transactivator with glu/asp-rich carboxy-terminal domain 2 (cited2) and suppresses the expression of hypoxiainducible genes in experimental ckd and uremia. FASEB J. 2013;27:4059-75.

79. Yamanaka S, Yokote S, Yamada A, Katsuoka Y, Izuhara L, Shimada Y, et al. Adipose tissue-derived mesenchymal stem cells in long-term dialysis patients display downregulation of pcaf expression and poor angiogenesis activation. PLoS One. 2014:9:e102311.

80. Tanaka S, Tanaka T, Nangaku M. Hypoxia as a key player in the aki-to-ckd transition. Am J Physiol Renal Physiol. 2014;307:F1187-95.

81. Mimura I, Kanki Y, Kodama T, Nangaku M. Revolution of nephrology research by deep sequencing: chip-seq and rna-seq. Kidney Int. 2014;85:31-8.

82. Mimura I, Tanaka T, Nangaku M. Novel therapeutic strategy with hypoxiainducible factors via reversible epigenetic regulation mechanisms in progressive tubulointerstitial fibrosis. Semin Nephrol. 2013;33:375-82.

83. Beyer S, Kristensen MM, Jensen KS, Johansen JV, Staller P. The histone demethylases jmjd1a and jmjd2b are transcriptional targets of hypoxiainducible factor hif. J Biol Chem. 2008;283:36542-52.

84. Krieg AJ, Rankin EB, Chan D, Razorenova O, Fernandez S, Giaccia AJ. Regulation of the histone demethylase jmjd1a by hypoxia-inducible factor 1 
alpha enhances hypoxic gene expression and tumor growth. Mol Cell Biol. 2010;30:344-53.

85. Mimura I, Nangaku M, Kanki Y, Tsutsumi S, Inoue T, Kohro T, et al. Dynamic change of chromatin conformation in response to hypoxia enhances the expression of glut3 (slc2a3) by cooperative interaction of hypoxia-inducible factor 1 and kdm3a. Mol Cell Biol. 2012;32:3018-32.

86. Tanaka T, Kojima I, Ohse T, Ingelfinger JR, Adler S, Fujita T, et al. Cobalt promotes angiogenesis via hypoxia-inducible factor and protects tubulointerstitium in the remnant kidney model. Lab Invest. 2005;85:1292-307.

87. Tanaka T, Matsumoto M, Inagi R, Miyata T, Kojima I, Ohse T, et al. Induction of protective genes by cobalt ameliorates tubulointerstitial injury in the progressive thy1 nephritis. Kidney Int. 2005;68:2714-25.

88. Ohtomo S, Nangaku M, Izuhara Y, Takizawa S, Strihou C, Miyata T. Cobalt ameliorates renal injury in an obese, hypertensive type 2 diabetes rat model. Nephrol Dial Transplant. 2008:23:1166-72.

89. Nordquist L, Friederich-Persson M, Fasching A, Liss P, Shoji K, Nangaku M, et al. Activation of hypoxia-inducible factors prevents diabetic nephropathy. J Am Soc Nephrol. 2015;26:328-38.

90. Vengellur A, Woods BG, Ryan HE, Johnson RS, LaPres JJ. Gene expression profiling of the hypoxia signaling pathway in hypoxia-inducible factor 1alpha null mouse embryonic fibroblasts. Gene Expr. 2003;11:181-97.

91. Vengellur A, Phillips JM, Hogenesch JB, LaPres JJ. Gene expression profiling of hypoxia signaling in human hepatocellular carcinoma cells. Physiol Genomics. 2005;22:308-18.

92. Higgins DF, Kimura K, Bernhardt WM, Shrimanker N, Akai Y, Hohenstein B, et al. Hypoxia promotes fibrogenesis in vivo via hif-1 stimulation of epithelial-to-mesenchymal transition. J Clin Invest. 2007;117:3810-20.

93. Fu L, Wang G, Shevchuk MM, Nanus DM, Gudas LJ. Generation of a mouse model of von hippel-lindau kidney disease leading to renal cancers by expression of a constitutively active mutant of hif1a. Cancer Res. 2011;71:6848-56.

94. Yu X, Fang Y, Liu H, Zhu J, Zou J, Xu X, et al. The balance of beneficial and deleterious effects of hypoxia-inducible factor activation by prolyl hydroxylase inhibitor in rat remnant kidney depends on the timing of administration. Nephrol Dial Transplant. 2012;27:3110-9.

95. Das F, Bera A, Ghosh-Choudhury N, Abboud HE, Kasinath BS, Choudhury GG. Tgfß-induced deptor suppression recruits mtorc1 and not mtorc2 to enhance collagen i (a2) gene expression. PLoS One. 2014;9:e109608.

96. Basu RK, Hubchak S, Hayashida T, Runyan CE, Schumacker PT, Schnaper HW. Interdependence of hif- $1 \mathrm{a}$ and tgf- $\beta /$ smad3 signaling in normoxic and hypoxic renal epithelial cell collagen expression. Am J Physiol Renal Physiol. 2011;300:F898-905.

97. He K, Chen X, Han C, Xu L, Zhang J, Zhang M, et al. Lipopolysaccharideinduced cross-tolerance against renal ischemia-reperfusion injury is mediated by hypoxia-inducible factor-2a-regulated nitric oxide production. Kidney Int. 2014;85:276-88.

98. Rozen-Zvi B, Hayashida T, Hubchak SC, Hanna C, Platanias LC, Schnaper HW. Tgf- $\beta /$ smad3 activates mammalian target of rapamycin complex- 1 to promote collagen production by increasing hif-1a expression. Am J Physiol Renal Physiol. 2013;305:F485-94.

99. Hanna C, Hubchak SC, Liang X, Rozen-Zvi B, Schumacker PT, Hayashida T, et al. Hypoxia-inducible factor- $2 \alpha$ and tgf- $\beta$ signaling interact to promote normoxic glomerular fibrogenesis. Am J Physiol Renal Physiol. 2013;305: F1323-31.

\section{Submit your next manuscript to BioMed Central and we will help you at every step:}

- We accept pre-submission inquiries

- Our selector tool helps you to find the most relevant journal

- We provide round the clock customer support

- Convenient online submission

- Thorough peer review

- Inclusion in PubMed and all major indexing services

- Maximum visibility for your research

Submit your manuscript at www.biomedcentral.com/submit 